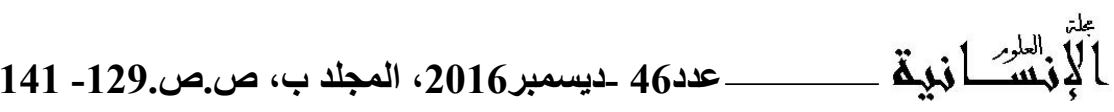

\title{
الخوصصة بين الضرورة الاقتصادية و حق العمل
}

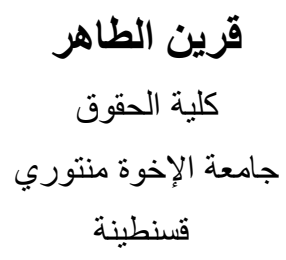

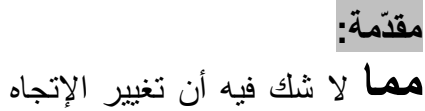
السياسي لكل دولة له نأثئير مباثر على تغيير النظام الإقتصادي القائم في تلك الدولة نظر اللعلاقة الوطيدة

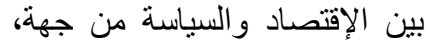
و التأثير الأنتبادل بينهما من جهة أخرى كما أن لذلائ انعكاس و اضيح

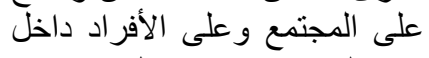

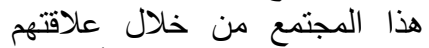

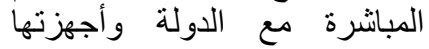
السياسية و الاقتصادية (1) .

لقد ظهر جليا تحول كثير من سياسات الدول في الفترة الأخيرة من النظام الإشتر اكي إلى النظام

الخوصصة في مفهومها العام هي التنازل عن التون المؤسسات العمومية للقطاع الخاص بإحدى الطرق الطياز

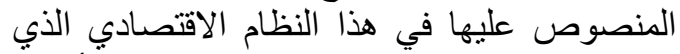

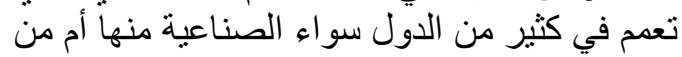

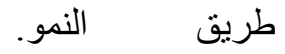
وتعنبر الخوصصة كضرورة اقتصادية لما نوفره

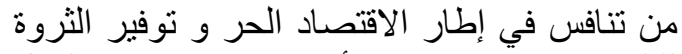

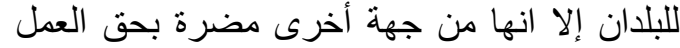

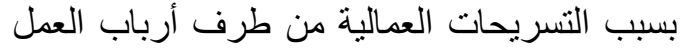

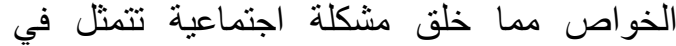
البطالة رغم الإجراءات القانونية التي اتخذتها الدول للتقليل منها.

\begin{abstract}
:
Privatization between economic necessity and the right to work privatization in the general concept is the waiver of the public institutions to the private sector in one of the methods set out in this economic system that is circulated in many States, whether the industrial ones, or are in the path of growth.

Privatization is an economic necessity for competing in the framework of the free economy and provide the wealth of the countries, but on the other hand, harmful to the right to work because of dismissals and Labor Party employers and creating a social problem of unemployment and despite the legal measures taken by States to reduce them.
\end{abstract}




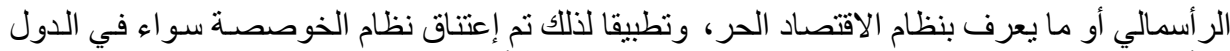

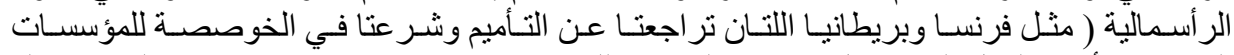

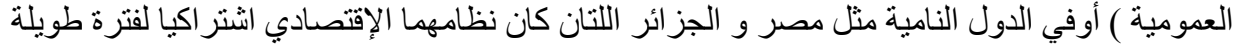

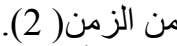

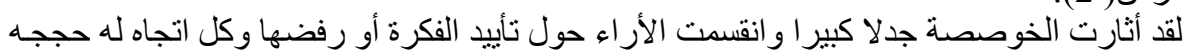

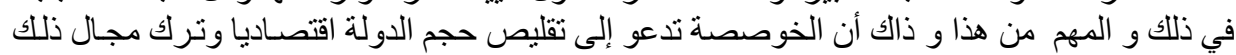

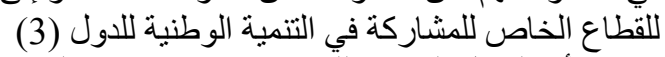

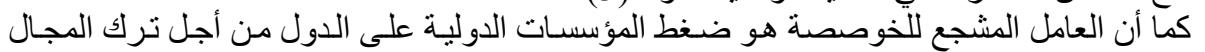

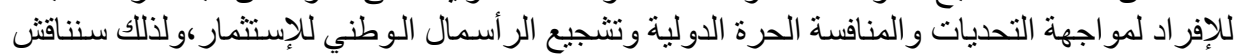

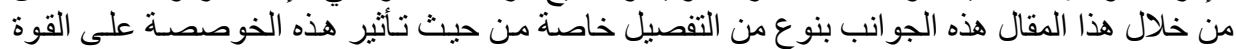

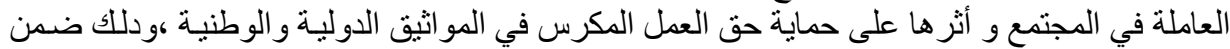

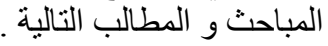

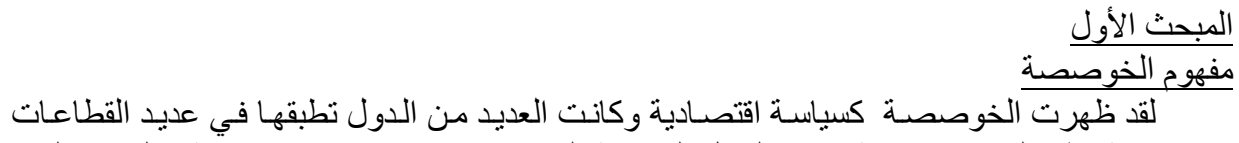

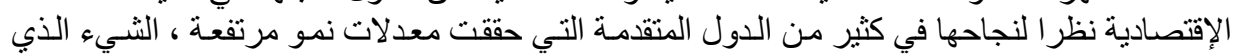

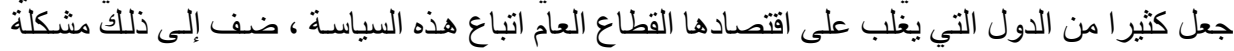

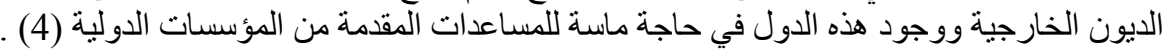

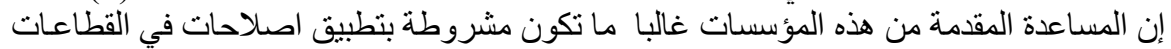

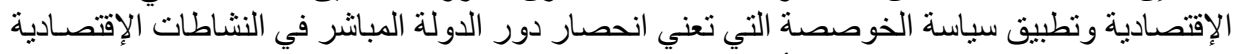

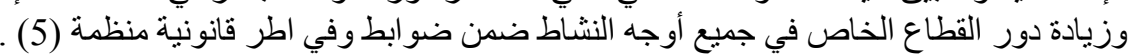

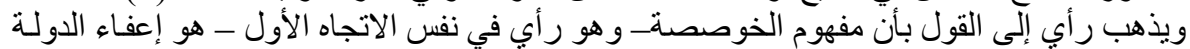

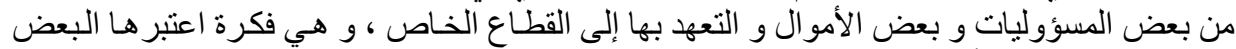

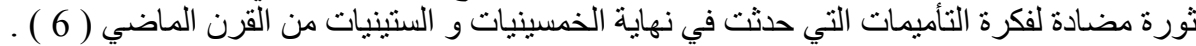

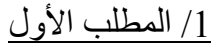
تعريف الذوصصة الأبة

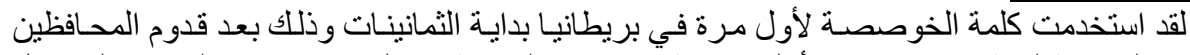

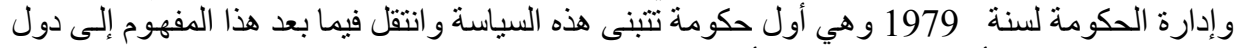

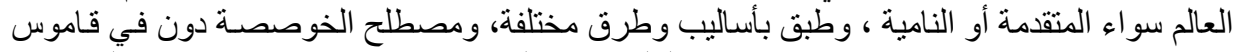

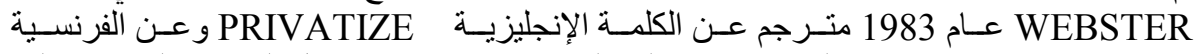
PRIVATISATION

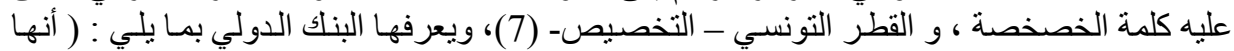
زيادة مشاركة القطاع الخاص في إدارة ملكية الأنشطة و الأصول التي تسيطر عليها الحكومـة أوتمتلكها

أما تعريف مدير المركز الإقتصادي للنمو الإقتصادي فيذهب إلى القول بأنها ( تعاقد أو بيع مؤسسات

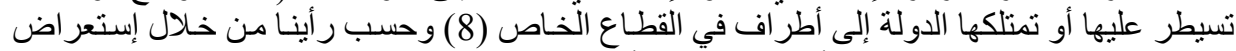

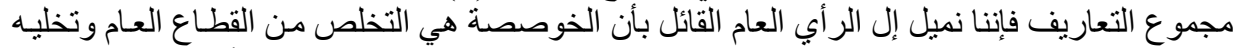

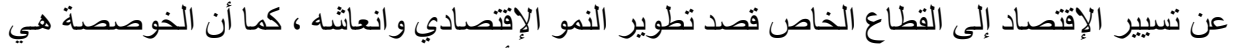

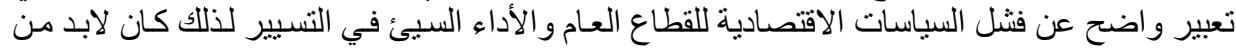




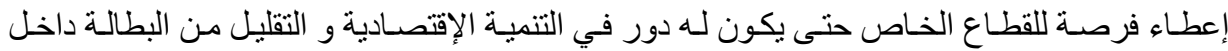

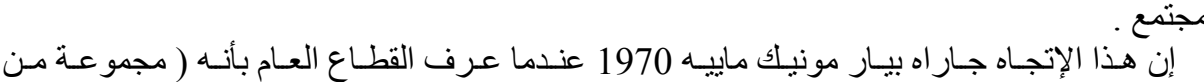

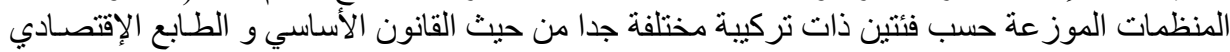

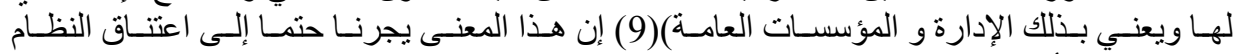

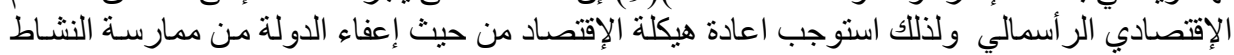

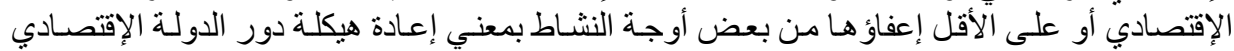

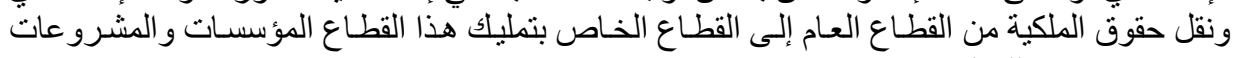

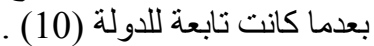
نشأة الخوصلب الثناني

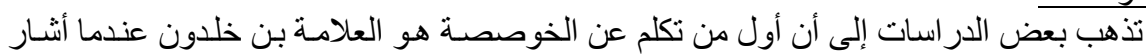

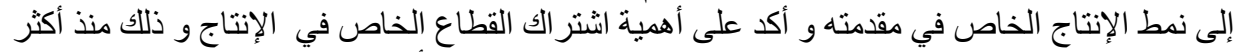

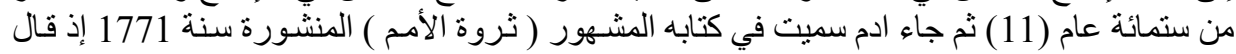
بالإعتماد على قوى السوق و المبادرات ألفردية كل ذلك من اجل الكل تحسين وتحقيق الكفاءة الإقتصادية وكذلك تقسيم العمل و التخصص التصف فيه (12) . وفي العصر الحديث فقد ظهرت فكرة الخوصصة من خلال الكتابات التي قدمها عالم الإدارة بيتر

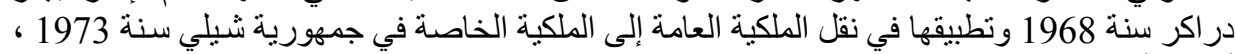

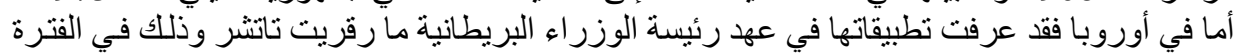

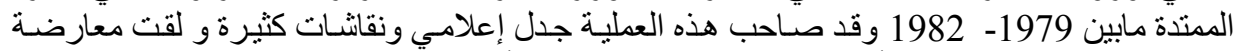

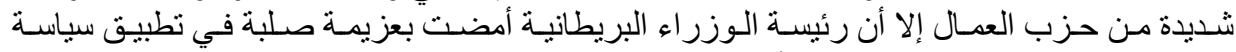

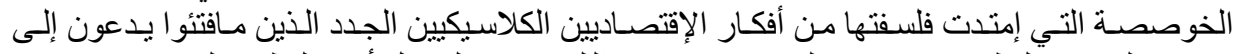

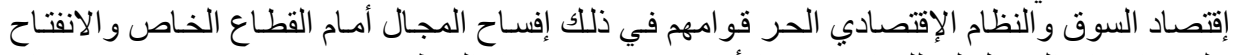

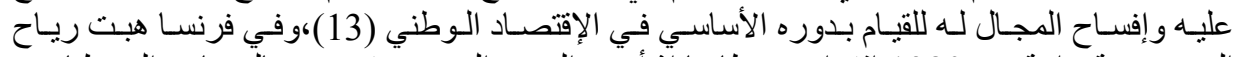

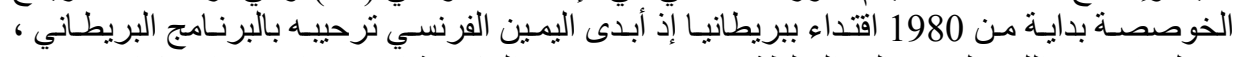

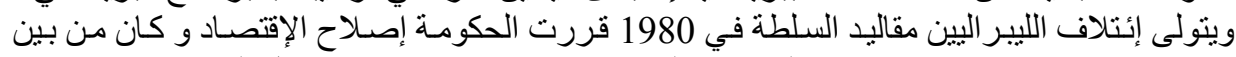

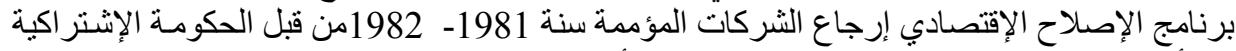

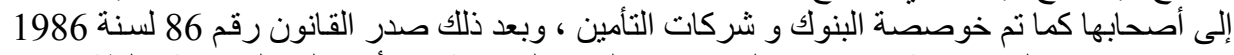

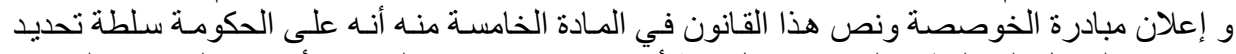

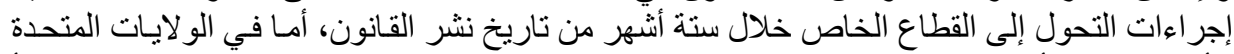

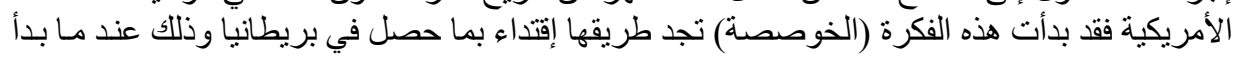

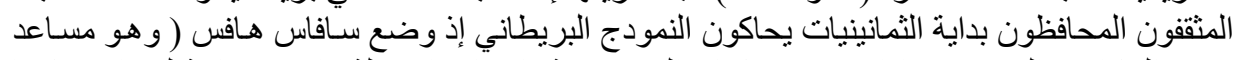

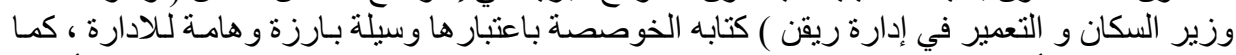

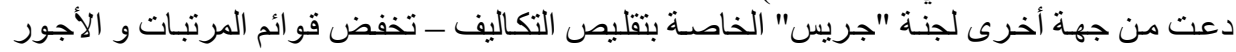

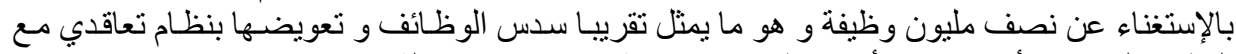

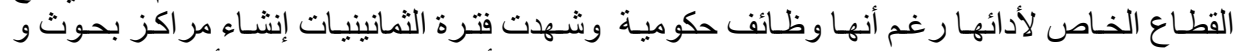

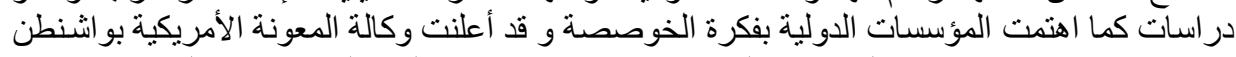

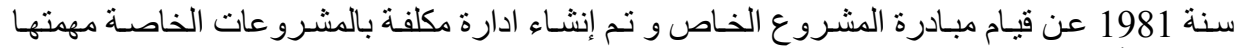

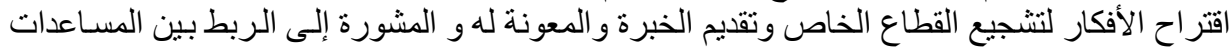

المعنوية و الجها المبذول للتحول إلى القطاع الخاص (14). 


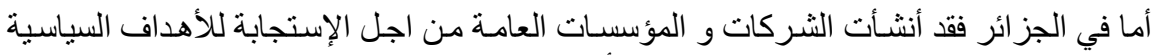

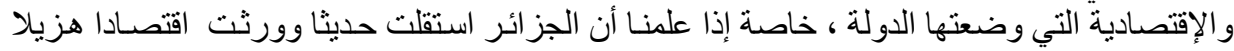

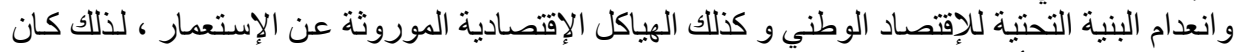

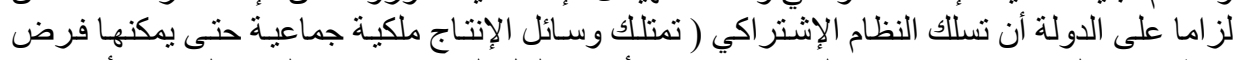

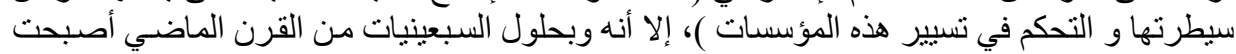

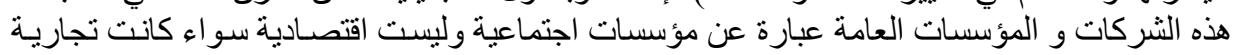

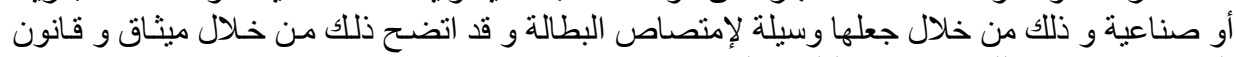

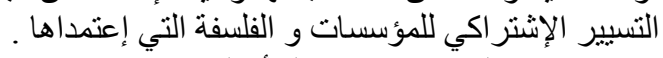

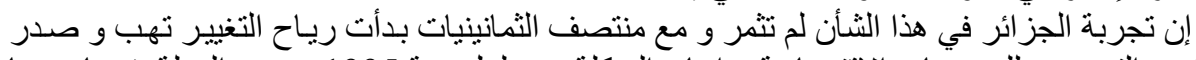

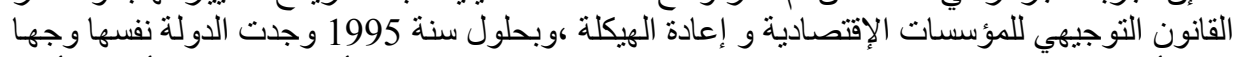

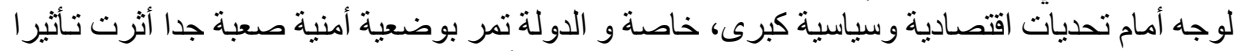

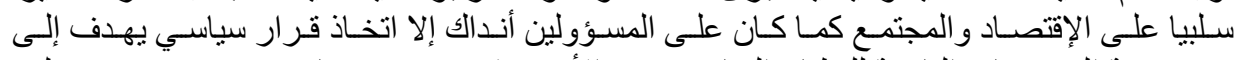

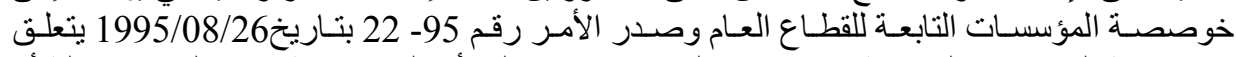

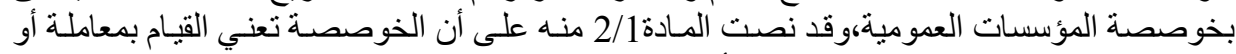

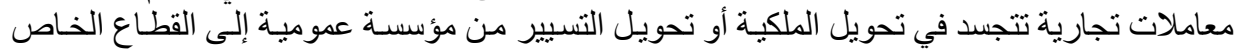

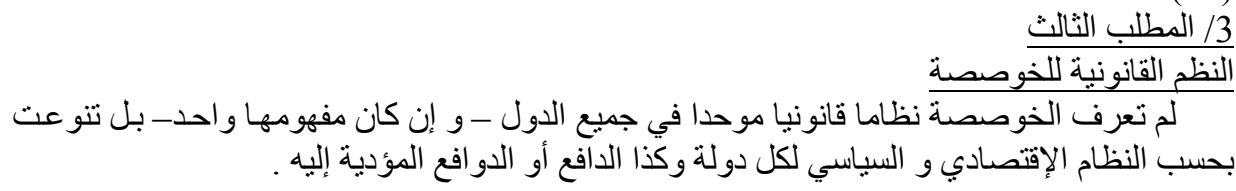

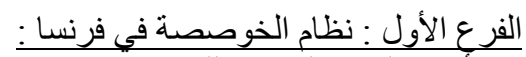

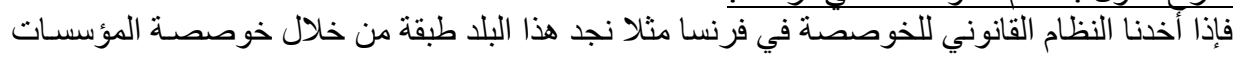

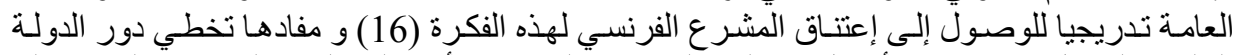

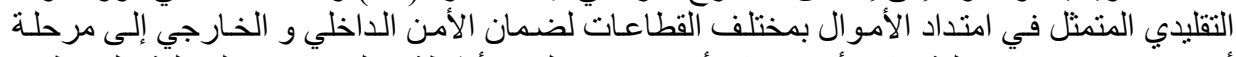

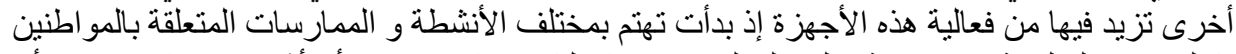

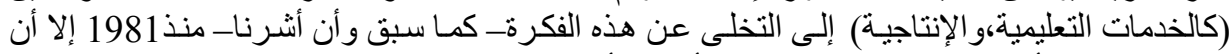

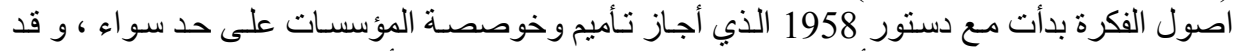

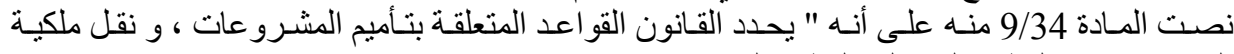

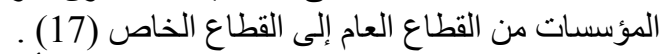

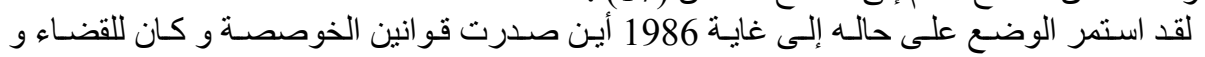

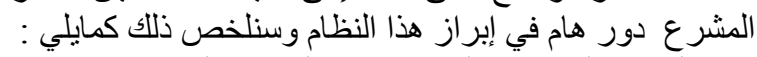

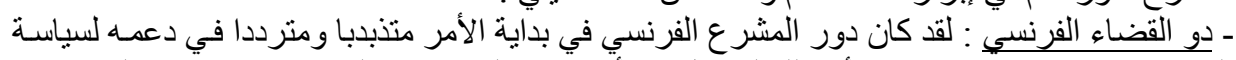

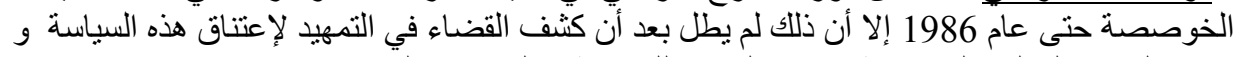

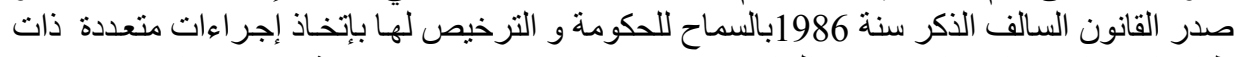

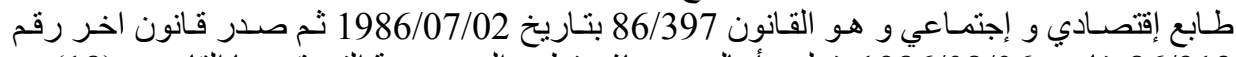

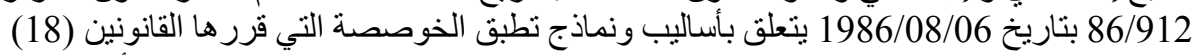

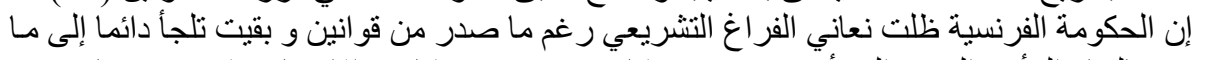

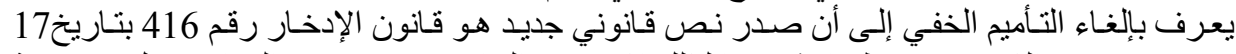

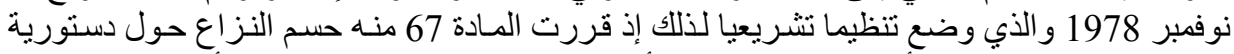

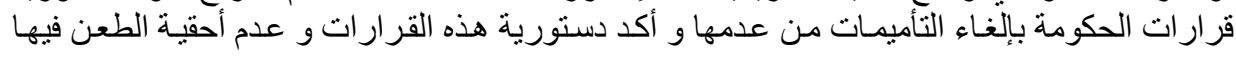




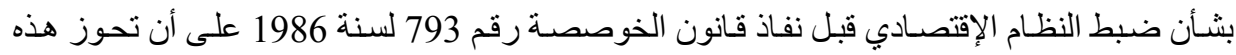

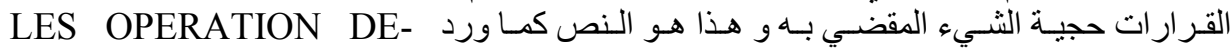
TRANSFERT DE PROPRIETE D'ENTREPRISES DU SECTEUR PUBLIC AU SECTEUR PRIVE INTERVENES AVANT L'ENTREE EN VIGUEUR DE LA LOI $\mathrm{N} \circ 86$ - 793 DU 2 JUILLET 1986 GOUVERNEMENT A - PRENDRE - DIVERSES - AUTORISANT LE MESURES - D'ORDRE ECONOMIQUE ET SOCIAL - NE PEUVENT ETRE LE GISLATIVE IL NE PEUT - AUCUN CAS ETRE - PORTE ATTEINTE - A L'AUTORITE DE LA CHOSE JUGEE.

و عليه فقد تعددت اتجاهات القضاء الفرنسي بثأن خوصصة المؤسسات العامة في المرحلة السابقة على صدور قو انين الخوصصة سنة 1986.

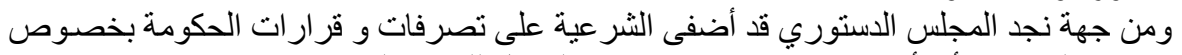

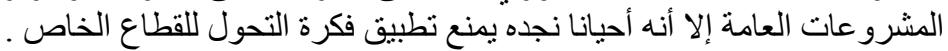

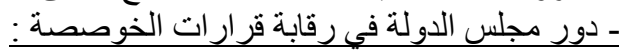

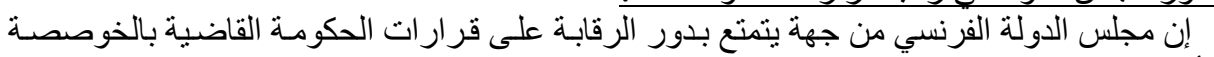

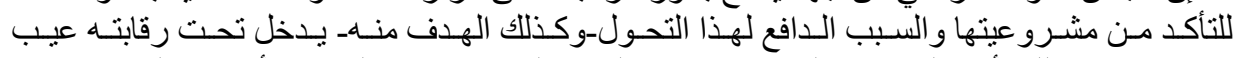

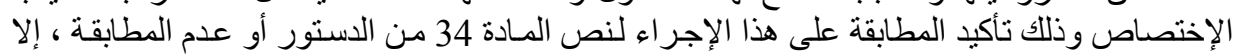

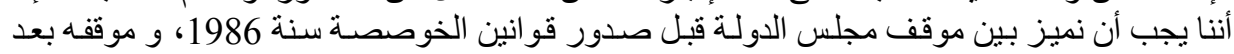

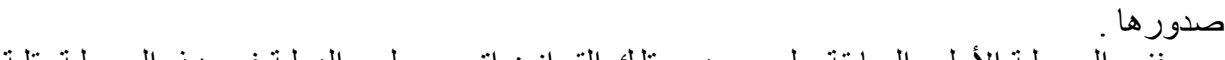

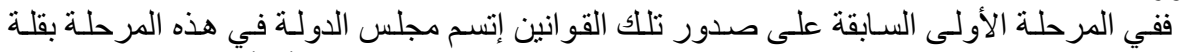

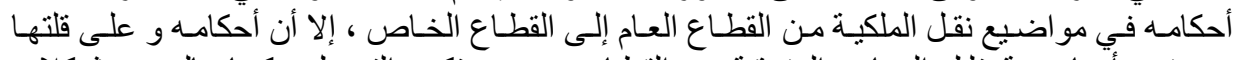

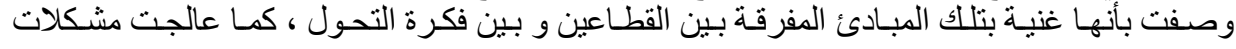

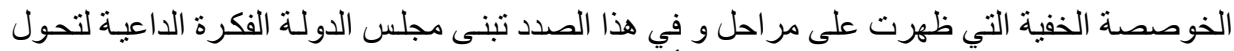

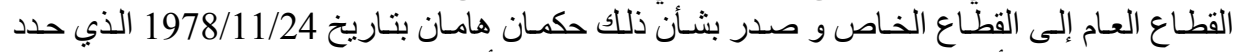

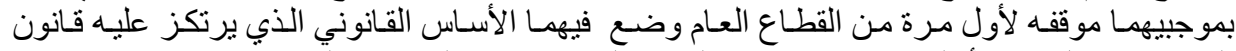

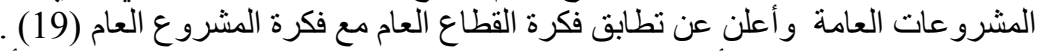

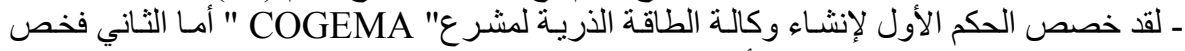

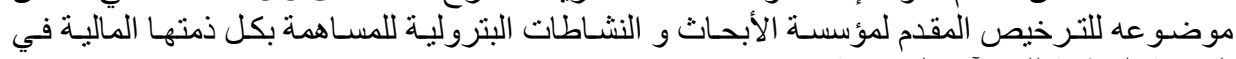

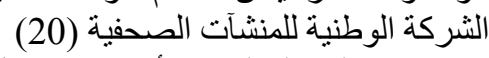

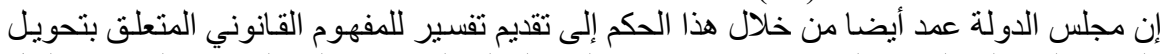

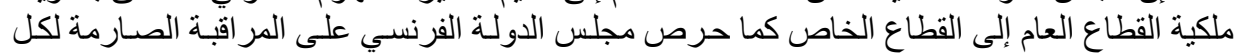

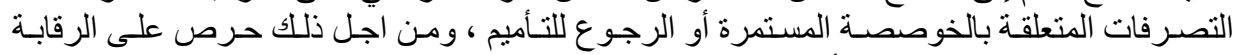

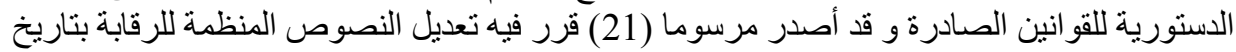

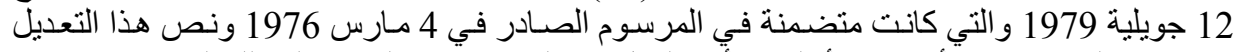

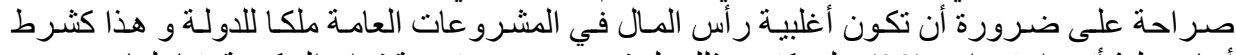

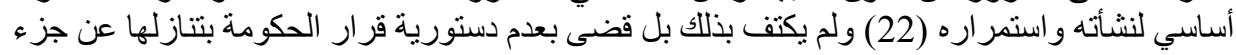

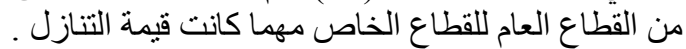

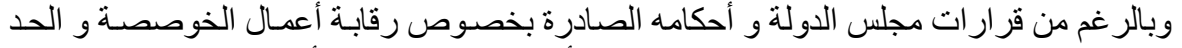

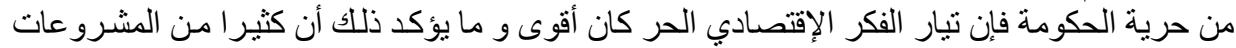

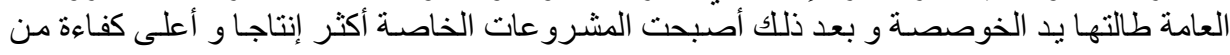




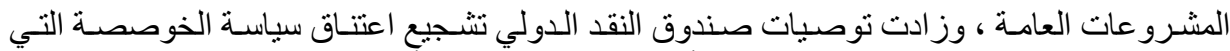

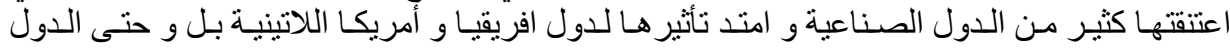

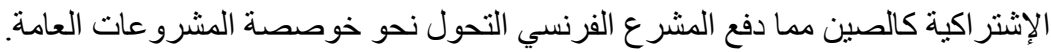

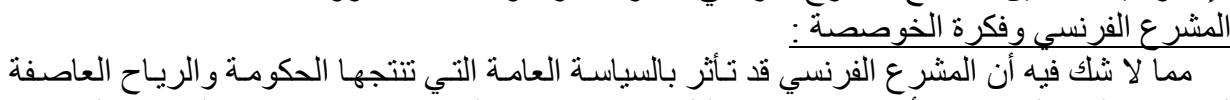

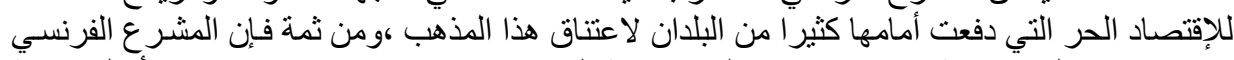

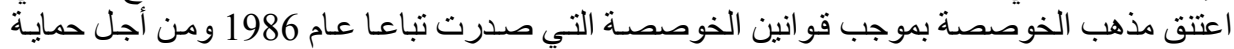

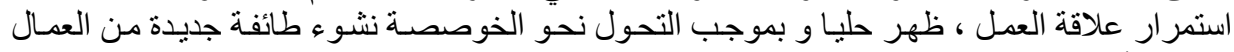

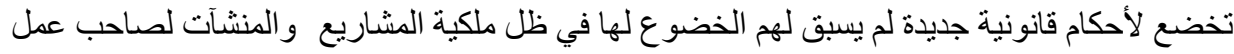
جديد. إن صدور قانوني 2 جويلية و 6 أوت 1986 أصبح الأساس القانوني لتحول الملكية من المشاريع

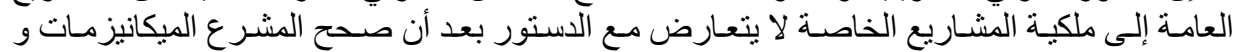

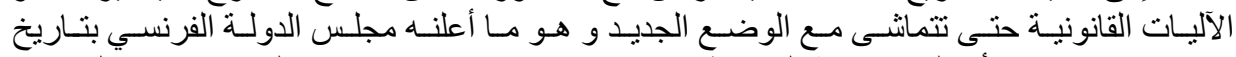

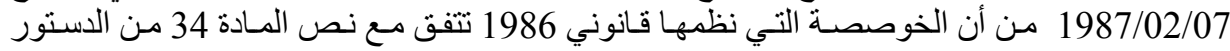
الفرنسي الصادر سنة 1958(تمت الإثارة إليه سابقا)

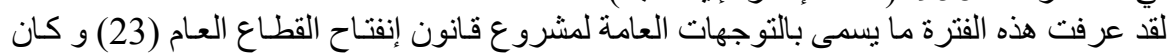

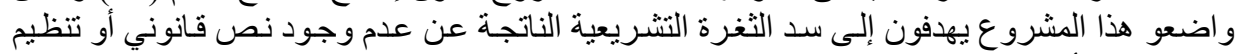

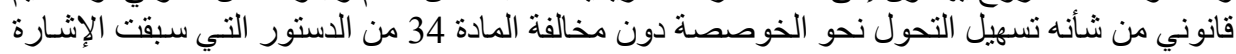

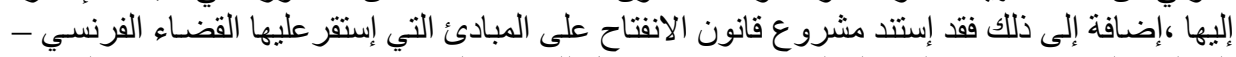

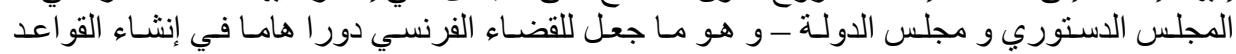

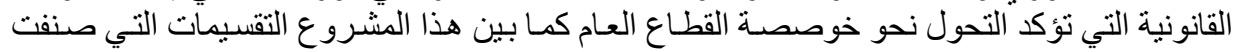

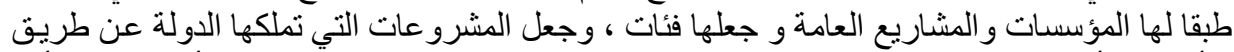

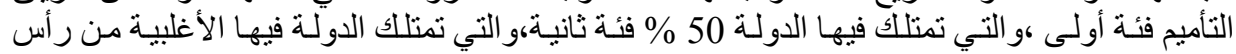

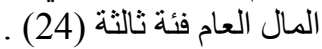

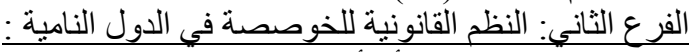

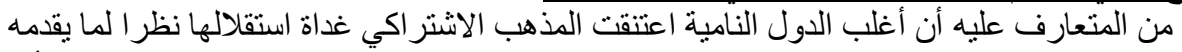

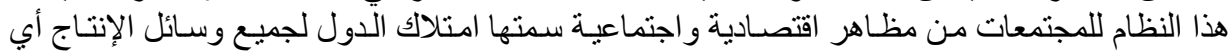

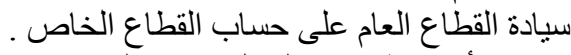

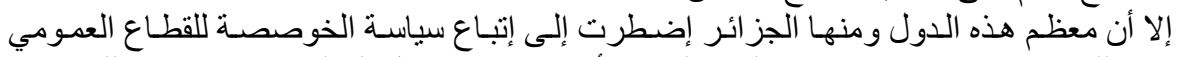

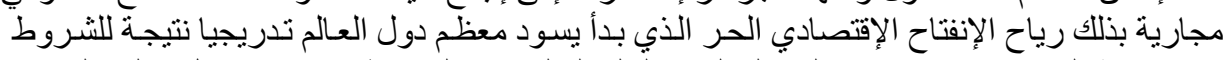

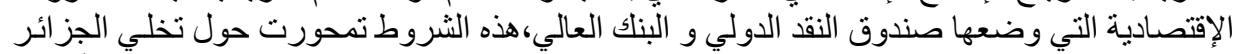

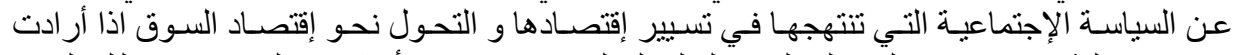

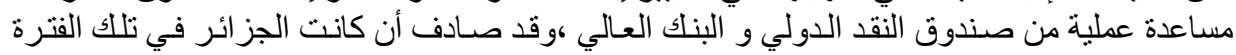

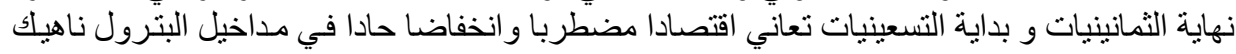

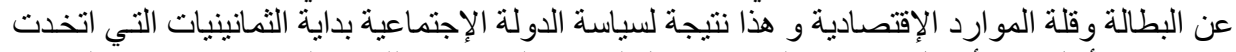

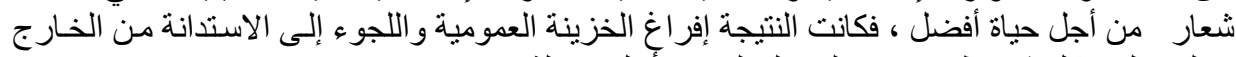

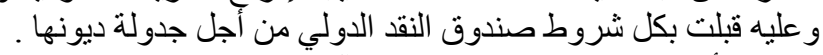

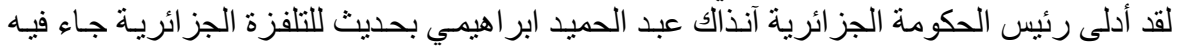

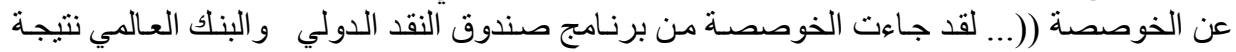

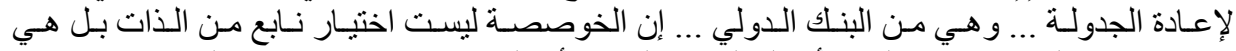
مفروضة من الخارج .... و الواقع أن الدولة هي السيدة لأن الخوصصـة جـاءت نتيجة لمفاوضـات (25) 


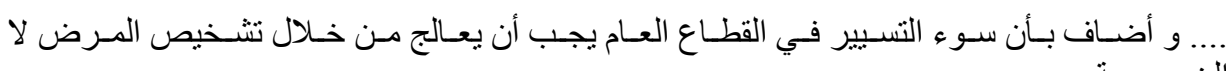

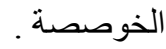

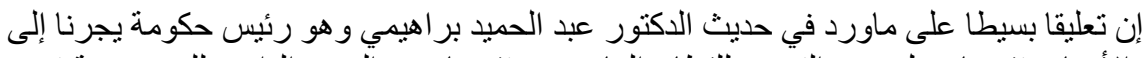

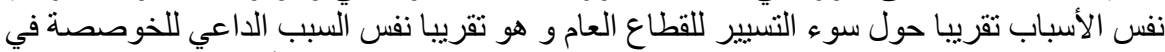

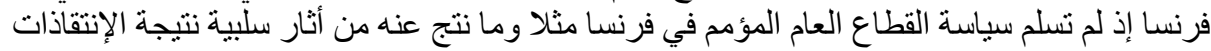

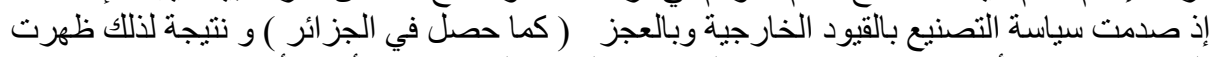

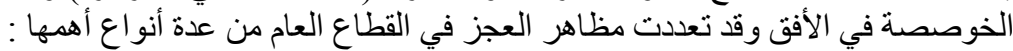

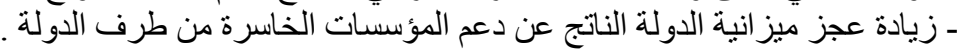
ـ ـ عجز القطاع العام عن مو اكبة النطور

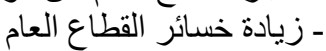

- زيادة نسبة التضخم وزيادة عدد العمال في مؤسسات القطاع العام (26) .

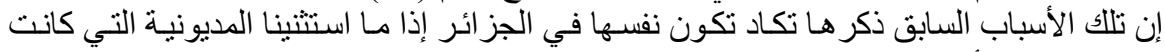

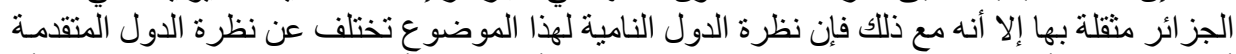

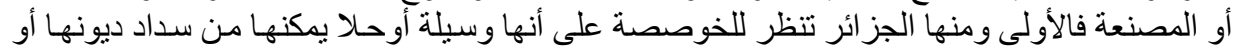

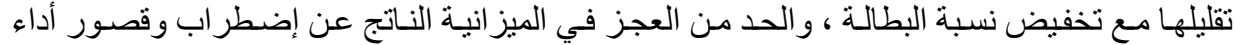

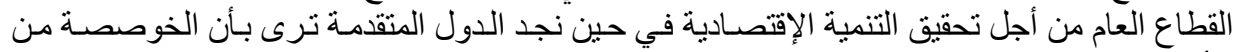

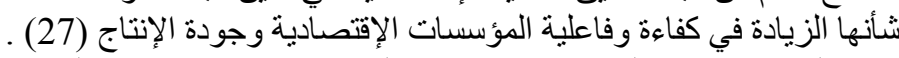

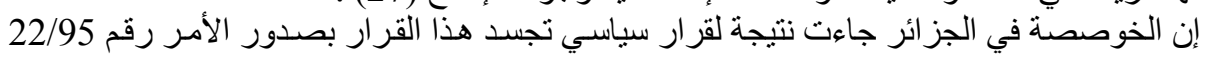

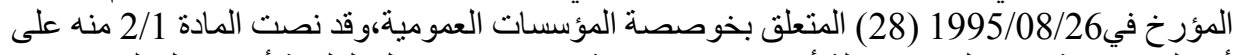

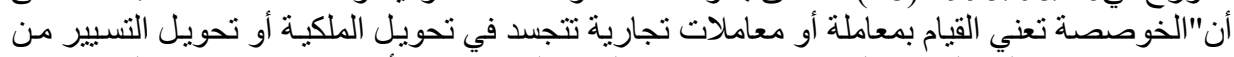

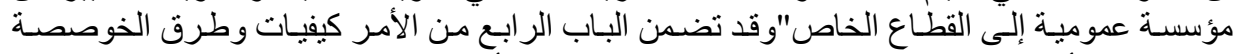

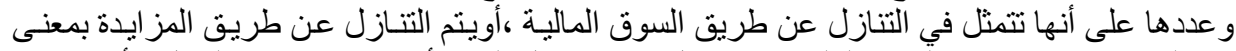

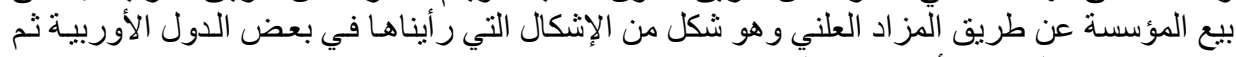

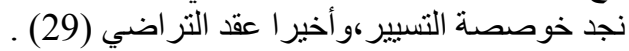

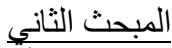

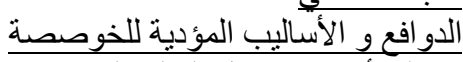

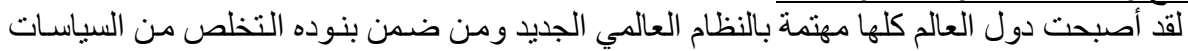

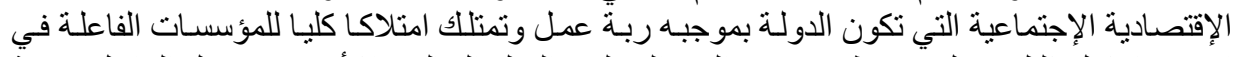

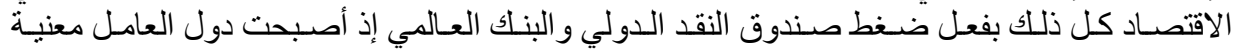

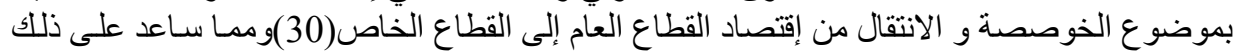

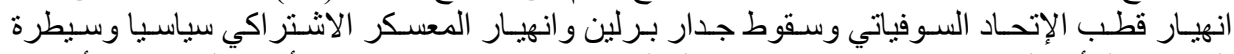

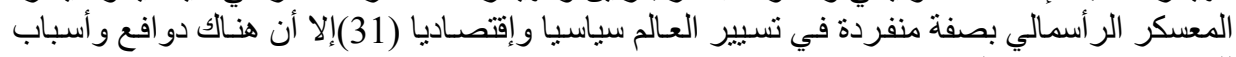

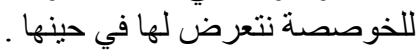

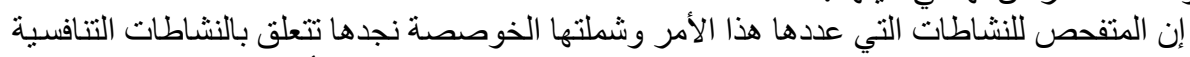

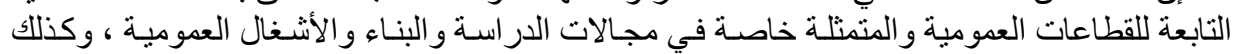

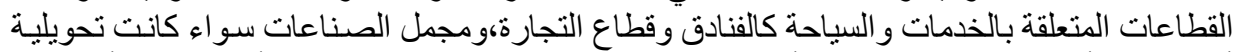

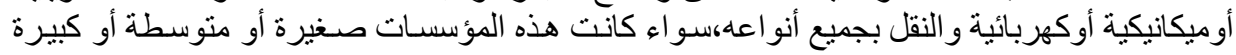

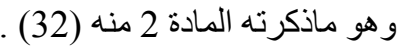

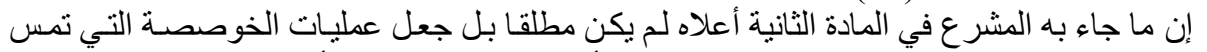

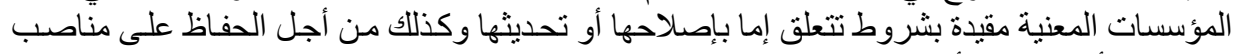

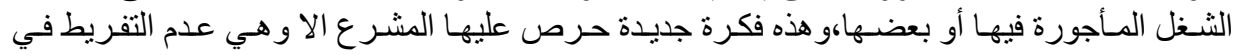




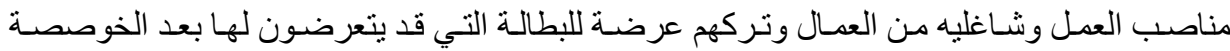

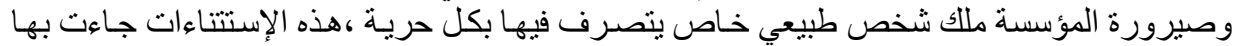

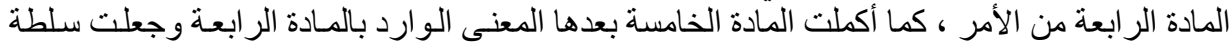

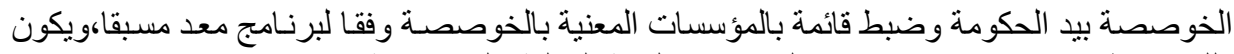

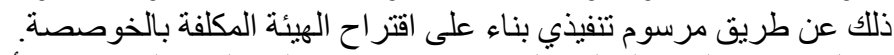

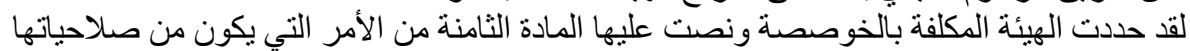

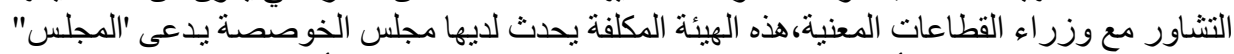

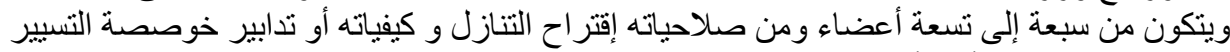

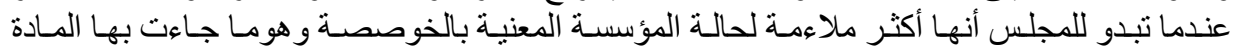

الدو افع الإقتصادية و الإن المالية

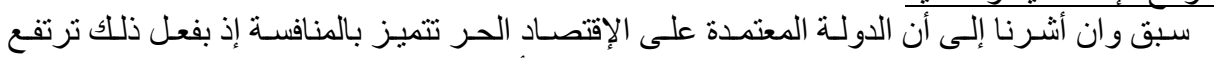

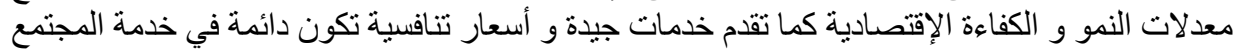

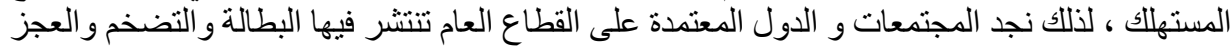

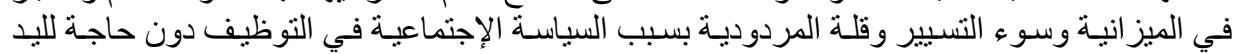

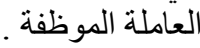

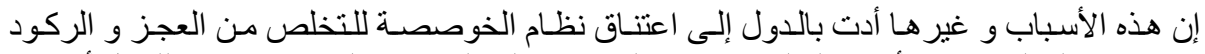

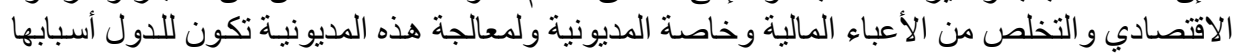

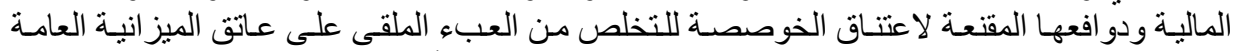

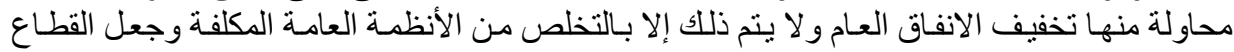

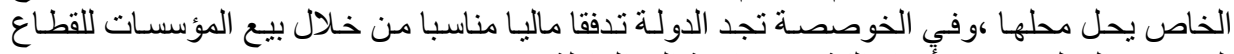
الخاص و التخلص من الأعباء الكثيرة وخاصة اليد العاملة (33) .

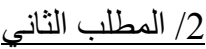

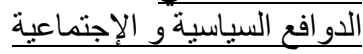

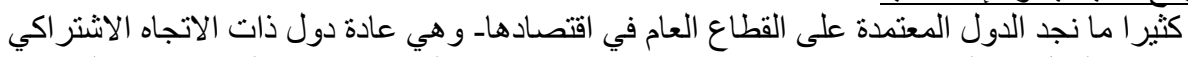

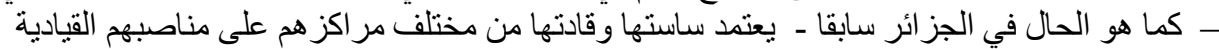

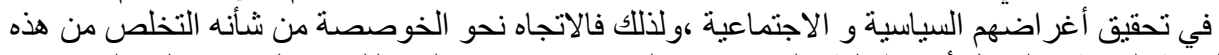

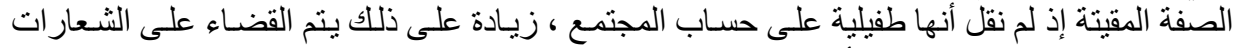

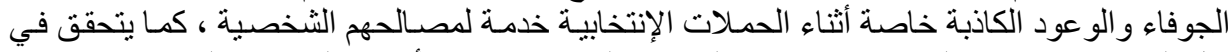

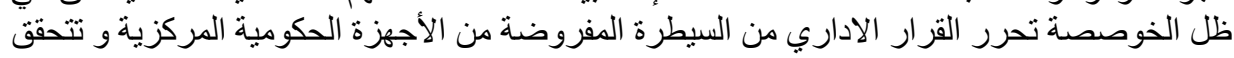

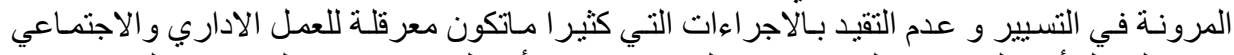

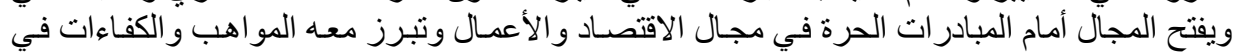

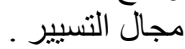

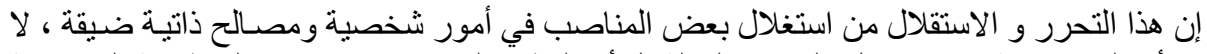

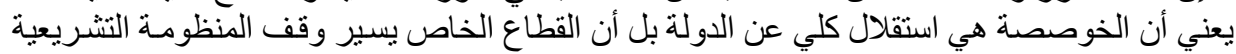

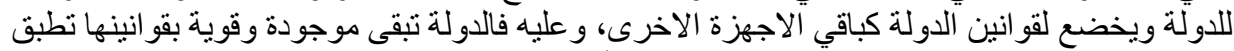

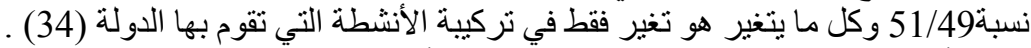

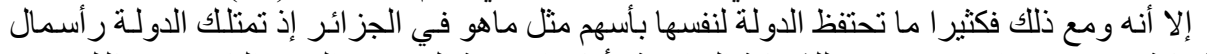

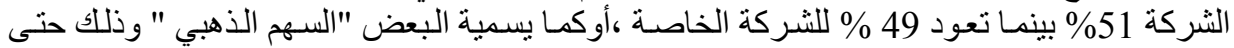




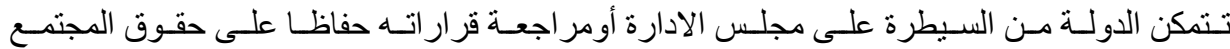

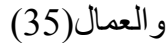
المبحث الثالث

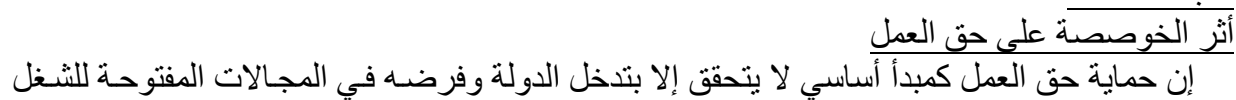

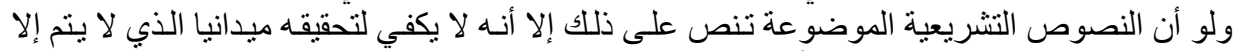

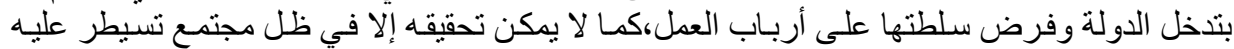

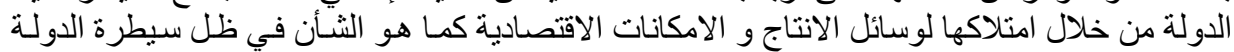

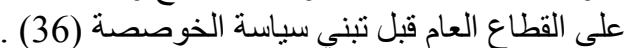

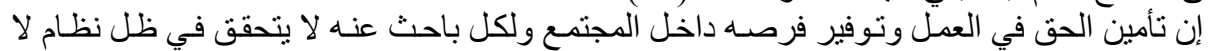

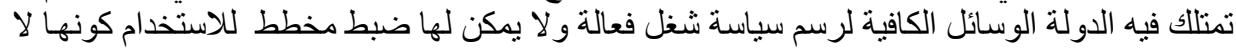

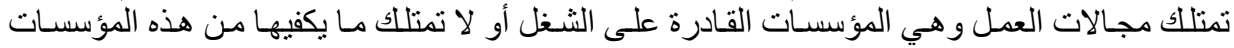

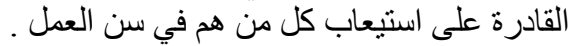

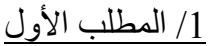

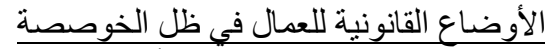

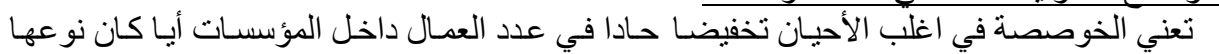

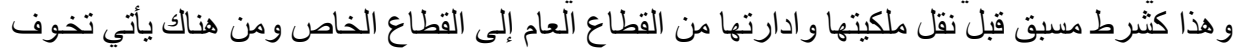

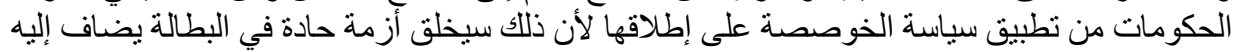

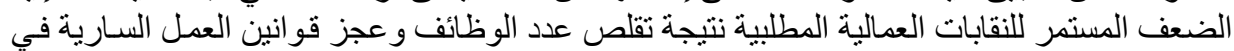

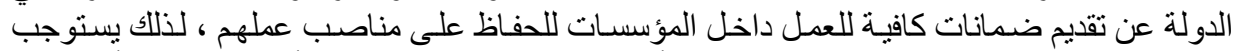

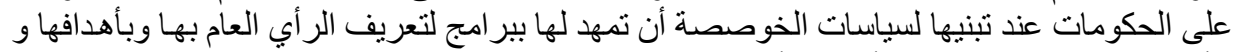

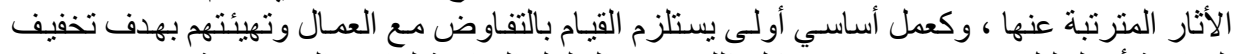

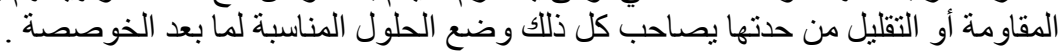

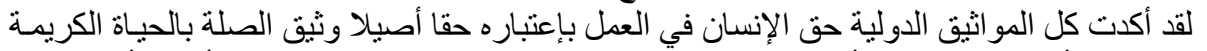

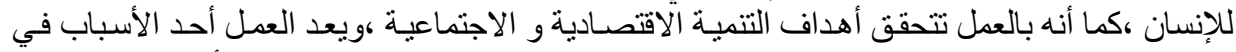

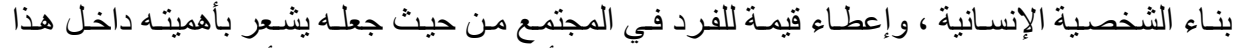

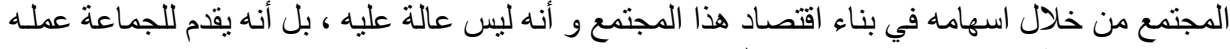

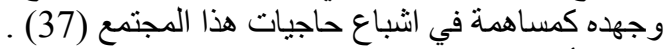

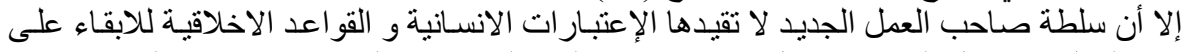

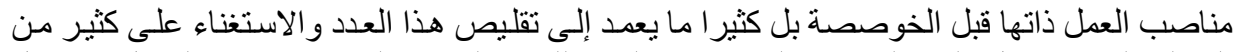

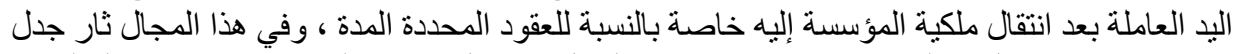

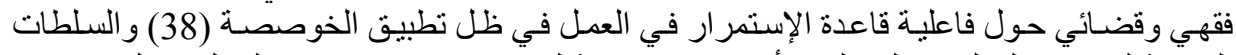

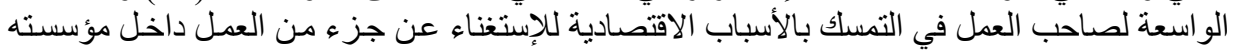

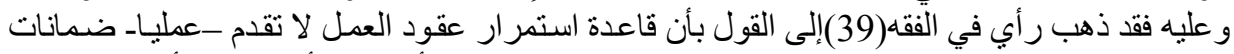

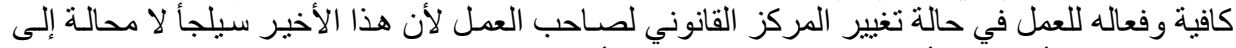

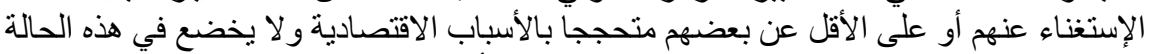

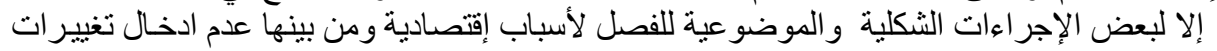

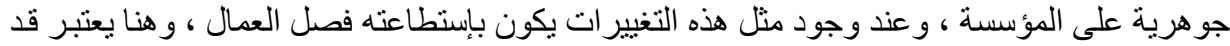

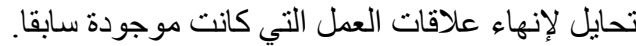

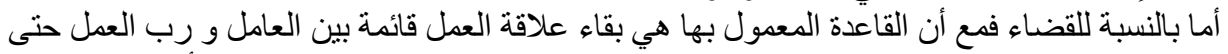
بعد تغير مالكها وحتى و لو لم تكن هذه العلاقة تربط رب العمل الجديد مباشـرة بالعامل أب الذي انتقلت 


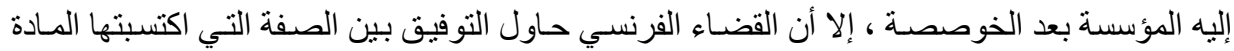

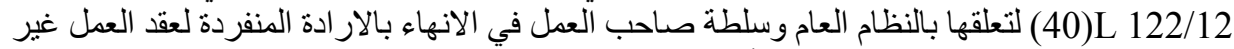

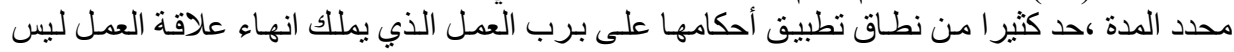

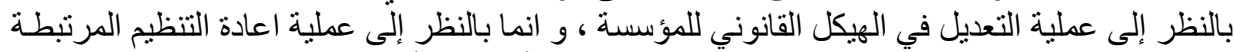

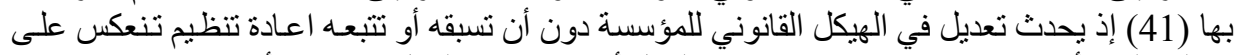

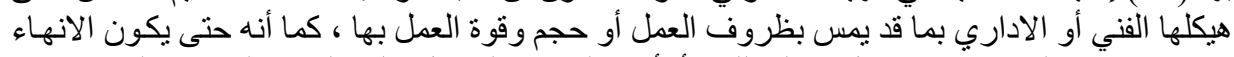

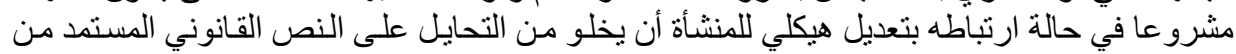

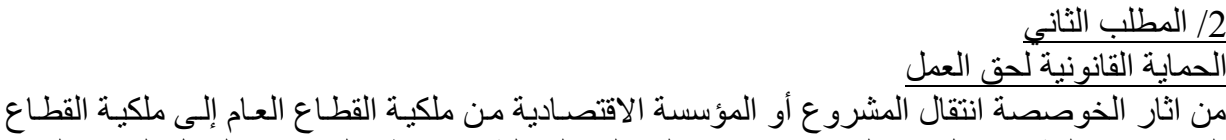

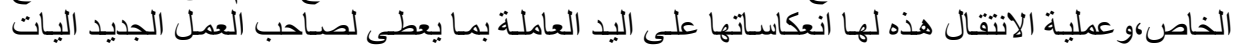

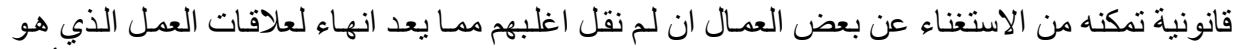

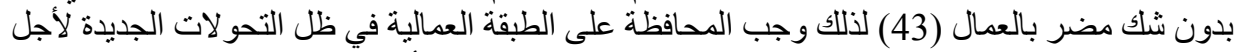

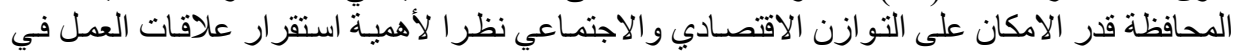

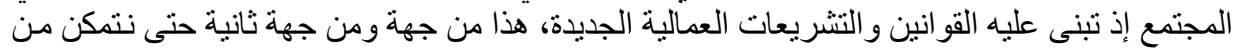

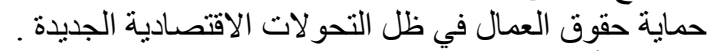

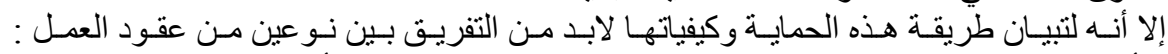

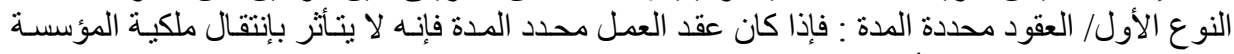

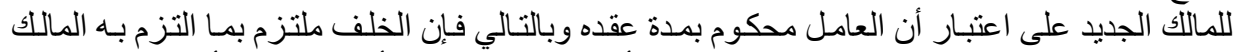

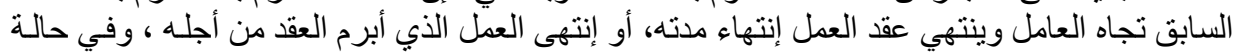

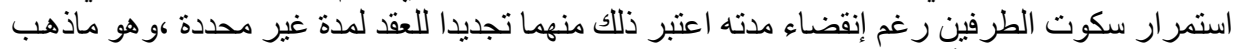

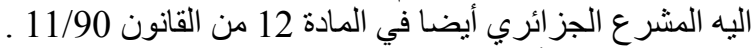

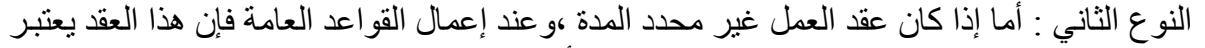

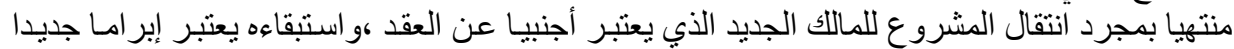

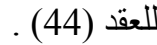

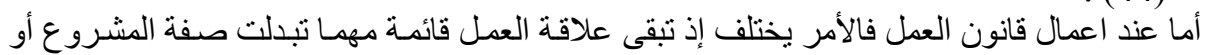

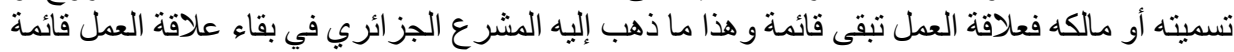

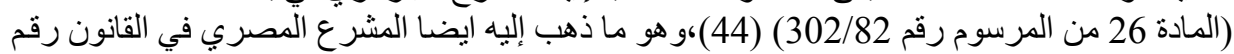

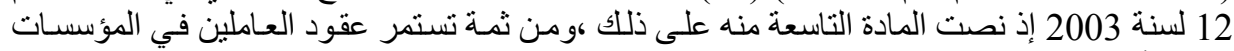

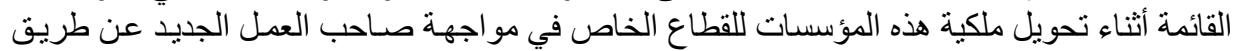

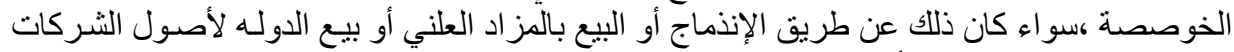

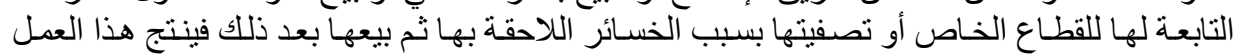

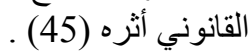
الخلاصـيـة: :تره

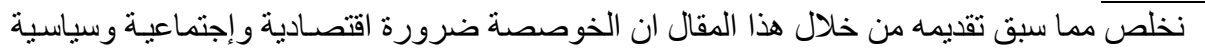

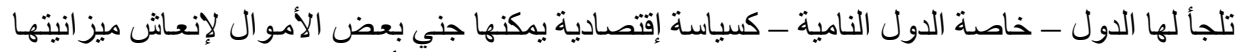

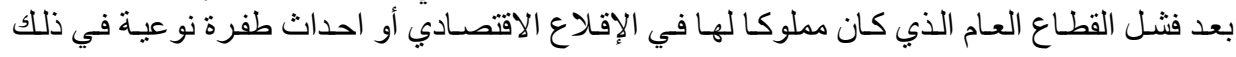


الاقتصاد وإما بسبب سوء التسيير أو سبب قلـة الموارد المالية التي لها علاقة بتمويل تلك الثركات و

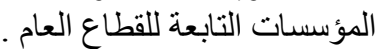

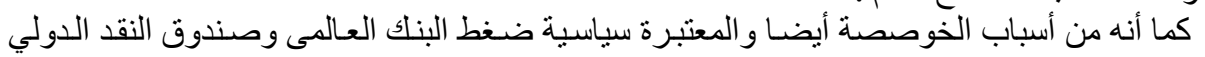

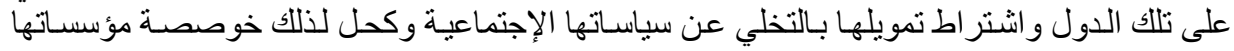

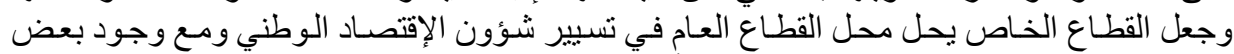

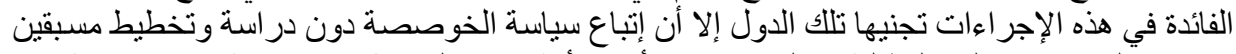

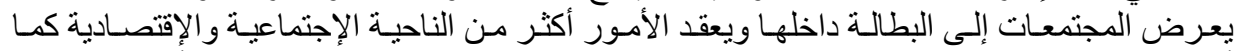

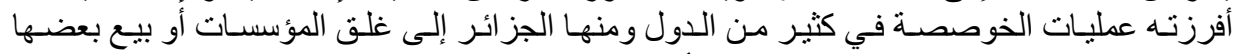

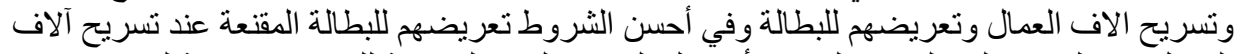

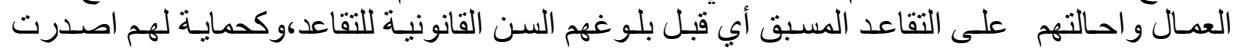

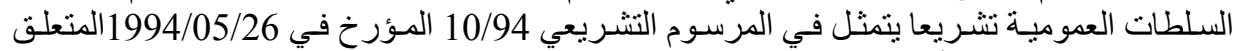

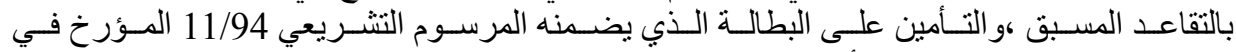

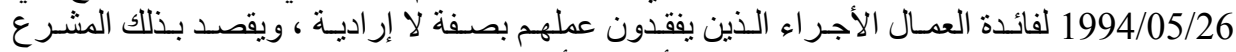
تسريحهم لسبب إقتصادي نتيجة غلق المؤسسة أو بيعها أو خوصصتها بإحدى الطرق المنصوص عليها

الهو امــش : جـهمد الحفناوي.تجربة مصر و الدول الر ائدة في مجال الخصخصة دار النهضة العربية

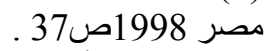
(2) -د. جمال أبو الفتوح محمد أبو الخير .أثر الخوصخصة على العلاقات الناتشئة عن عقد العمل دار

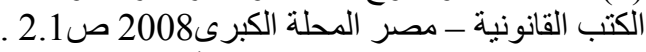

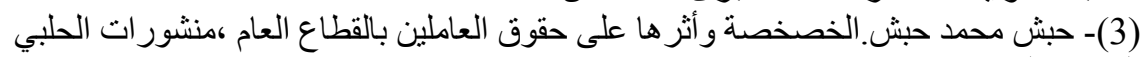

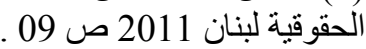

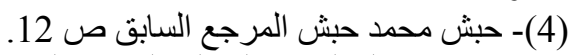
(5) - د.محمد خالد المسار العمالي الجديد والقرن الواحد و العشرين الطبعة الأولى دار المعارف 1998 ص 14. (6)- جمال محمود الكردي :النظم القانونية للخصخصة في القانون المقارن و القانون الدولي الخاص

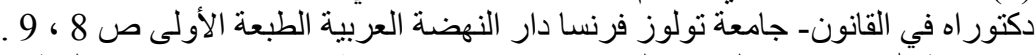

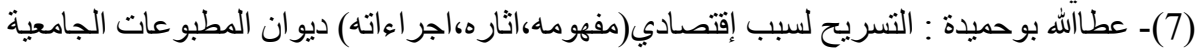

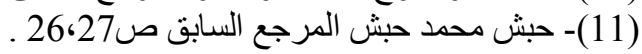

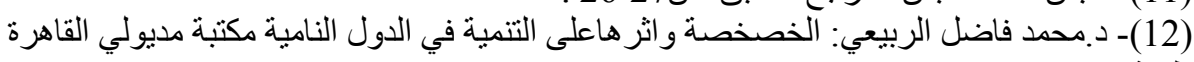

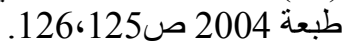
(13)- د.أحمد السيد :الخصخصة ودور ها في تتمية وتطوير الأنظمة الإقتصاديةو المعاصرة- دار

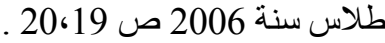
(14)ـ د.خلاف عبد الجابر ، خلاف : ندوة التحو لات الاقتصادية و أثر ها على علاقات العمل ، مركز

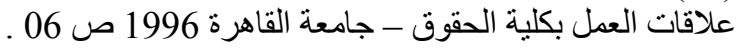

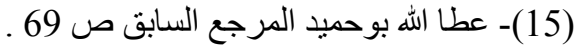


(16)- ANDREF (W) (LES ENTREPRISES PUBLIQUES UNIVERSITE UES-SCIENCES-SOCIALES DE GRENOBLE,COURS DES SCIENCES ECONOMIQUES 1985.P.23.

(17)- د.جمال أبو الفتوح محمد أبو الخير ، أثر الخصخصة على علاقة العمل - دراسة مقارنة بين

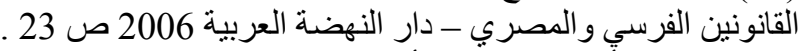

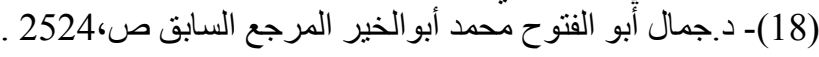

(19)- CE . ASS : 24/11/1978 - SYNDICAT NATIONAL DU PERSONNEL

L'ENERGIE - ATOMIQUE ;- CE ASS : 24/11/1978, SIEUR - SCHWARTZ

- ET- EUTRE CONCL . NOT - LATOUNERIE . A.J.D.A.

MARS 1979.P .42

أورده د.جمال أبو الفتوح المرجع السابق ص35-34 ـ ـ

(20)- DELION ( A.G) LA NOTION - D'ENTREPRISE - PUBLIQUE

A.J.D.A AVRIL 1979.P.3 .

(21)- DECRIT DU 12/07/1979 .MODIFIANT. LE DECRET DU 04/03/1976 . PORTANT-APROBATION- DES-STATUS DE LA COMPAGNIE-

GENERAL- DES - MATIERES NUCLEARES .

(22)- CE-ASS - 26 MARS 1982 - SYNDICAT NATIONAL DU

PERSONNEL DE L'ENERGIE - ATOMIQUE CEDT.R.D.I 1982 P 1716

أورد د. جمال أبو الفتوح المرجع السابق ص 36 .

(23) LE PROJET DE LOI N 1193 DEPOSE SUR LE BURE AU DE

L'ASSEMBLEE - NATIONAL LE 28.OCTOBRE 1982 .

(24)- JUYON (X) LES PREVATISATION EN - FRANCE NANTES 1995.P47.

(25)- د.عبد الحميد بر اهيمي(حصة متلفزة لقناة MBC قدمت يوم الجمعة -13 جوان 1997 س 6 سورة 6 مساء أورده الدكتور .عطالله بوحميدة المرجع السابق 68 . 68 .

(26)- RAPP(L) LE SECTEUR - PUBLIC - FRANÇAIS ENTRE

NATIONALISATION ET PREVATISATION - A.J.D. N`5 1987.P 319.

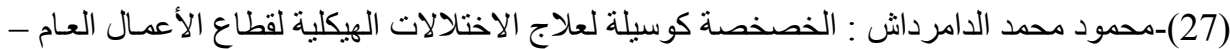

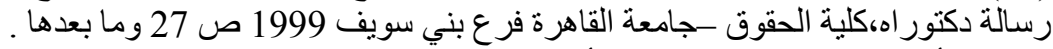

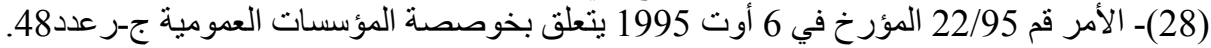

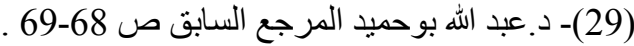

(30)-د.مصطفى رشدي شيحة :النظريـة العامـة للنشـاط الدولي الماليـ الدار الجامعية بيروت 1993262 ص

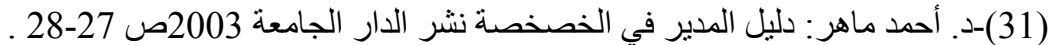

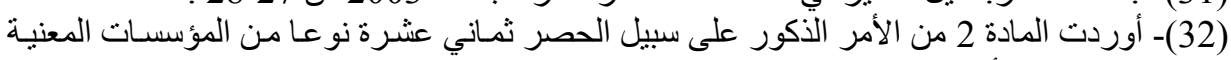

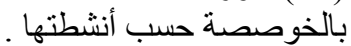

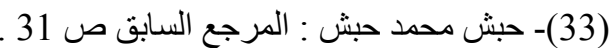

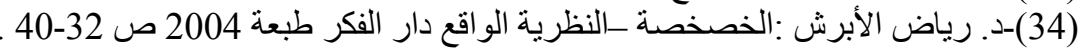

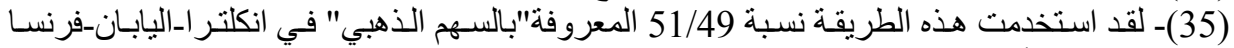

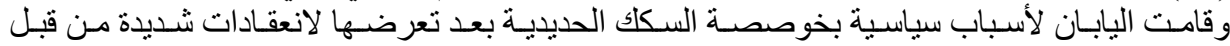

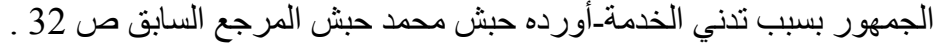


(36)- الحسن محمد محمد سباق:أثر الخصصـة على حقوق العمال - رسـالة دكتور اه جامعة أسيوط 232 ص صدم 2006

(37)- د.محمود سلامة جبر :الحماية الدستورية للحقوق الأساسية في العمل در اسة مقارنة بدون دار نشر

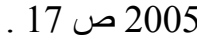

(38)- د.حسن عبد الرحمان قدوس :إنهاء علاقة العمل لأسباب اقتصادية مكتبة الجلاء بالمنصورة

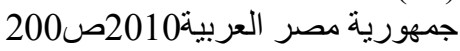
(39)- د.فتحي عبد الرحيم :مبادئ قانون العمل و التأمينات الاجتماعية ص 200 أورده الحسن محمد

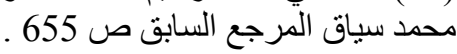
(40)- المادة 122/12 من قانون العمل القرنسي تنص على بقاء علاقة العمل القائمة حتى بعد تغير مالكها.

(41)-د. عبد الرحمان قدوس المرجع السابق ص 118 (42)- CON.D'ETAT. 21/MARS 1986 SOMM - DR.DU TRAVAIL No73

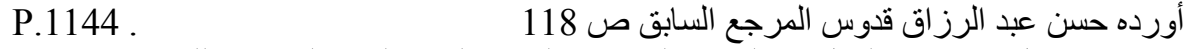
(43)- د.جمال زكي عقد العمل في القانون المصري الطبعة الثرني الثانية الهيئة الهصرية للكتاب 1982 ص

(44)- د.محمد محسن نجاز : الضمانات القانو نية للعاملين في ضوء الخصخصة مكتبة دار الثعاع طبعة 26 ص 2002 (45)- د. خليل أحمد حسن قدادة : أثر العقد بالنسبة للحلف الخاص وفقا لأحكام القانون المدني الدصري

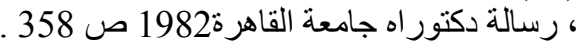

